\title{
Singapore Urological Association Clinical Guidelines for Male Lower Urinary Tract Symptoms/Benign Prostatic Hyperplasia
}

\author{
Singapore Urological Association Male Lower Urinary Tract Symptoms/Benign Prostatic Hyperplasia
}

Guidelines Committee 2015

\begin{abstract}
The first clinical guidelines for male lower urinary tract symptoms (LUTS)/benign prostatic hyperplasia (BPH) were published in 2005. An update is urgently needed in view of BPH being recognised as one of ten chronic illnesses by the Ministry of Health, Singapore. This review summarises the definition of BPH and the epidemiology of male LUTS/ BPH in Singapore. BPH can be phenotyped with noninvasive transabdominal ultrasonography, according to intravesical prostatic protrusion and prostate volume, and classified according to severity (staging) for individualised treatment. At the initial evaluation, the majority of patients (59\%) can be managed with fluid adjustment, exercise and diet; $32 \%$ with medications, using alpha blockers and/or 5-alpha reductase inhibitors for prostates weighing more than 30 g; and $9 \%$ with surgical intervention for more advanced disease. The 2015 guidelines comprise updated evidence that will help family medicine practitioners and specialists manage this common ailment more cost-effectively.
\end{abstract}

Keywords: benign prostatic hyperplasia, clinical guidelines, intravesical prostatic protrusion, male lower urinary tract symptoms, staging of clinical BPH

\section{INTRODUCTION}

With its ageing population, male lower urinary tract symptoms (LUTS)/benign prostatic hyperplasia (BPH) will become the most common urological condition in Singapore. Family physicians (FPs) and urologists play complementary roles to each other in the management of male LUTS/BPH. A body of recommendations will ensure seamless care flow between the specialties.

The first local clinical guidelines for male LUTS/BPH were published in 2005.(1) Hence, the Singapore Urological Association formed a committee to review and update these guidelines based on the latest medical literature and expert consensus. The updated version is patient-centred, with efforts made to avoid overgeneralisation that lacks due consideration for patients' social and financial backgrounds. We adhered to a renewed understanding of the pathophysiology of the disease and the following hierarchy of healthcare: saving lives, preserving organs and relieving symptoms. We included Singaporean and Asian data to reflect the importance of the cultural and lifestyle impact on LUTS. We also provided evidence to support recommendations for $\mathrm{FPs}^{\prime}$ clinical practice. Together with an update on urological practice and techniques, we also created care flow plans to facilitate decision-making in the clinics of FPs and urologists.

Our recommendations are made from the perspectives of both FPs and urologists. They are graded as 'A' (highly recommended), 'B' (recommended), 'C' (may be considered) and 'D' (not recommended). We decided not to state the level of evidence, to avoid clinical judgements that are masked by overgeneralisation of evidence alone.

\section{DEFINITION OF BPH}

$\mathrm{BPH}$ is one of the causes of male LUTS, and not the only cause. The diagnosis of clinical BPH is frequently equated with benign prostatic enlargement causing obstruction. In fact, many international guidelines have defined benign prostatic obstruction as blockage from benign prostatic enlargement due to the histological presence of BPH. ${ }^{(2)}$ However, local studies have shown that patients with clinically non-enlarged prostates can still have obstruction. ${ }^{(3)}$ This is because clinical BPH is not diffuse enlargement but nodular hyperplasia that is similar to fibroadenoma of the breast. ${ }^{(4)}$ Obstruction, therefore, depends on the site rather than the size of the adenoma. An adenoma at the periurethral zone giving rise to the middle lobe, even though small, would cause significant obstruction, while an adenoma situated deep in the transitional zone giving rise to the lateral lobes may not cause significant obstruction. Therefore, we defined clinical BPH as prostatic adenoma/adenomata causing varying degrees of obstruction, with or without symptoms.

\section{SYMPTOMATOLOGY OF BPH}

Male LUTS is a constellation of symptoms. There is no one symptom that is synonymous with $\mathrm{BPH}$. Thus, it is imperative to broaden the differential diagnosis to include other diseases such as bladder dysfunctions, carcinoma, infection or stones. Male LUTS can be categorised into storage and voiding symptoms. Storage symptoms usually arise from responses of the bladder to obstruction. These include urgency, frequency and nocturia, which may indicate irritation to the bladder or an overactive bladder. Voiding symptoms include hesitancy, slow flow, 
intermittency and the sensation of incomplete voiding, which often indicate bladder outlet obstruction but are sometimes due to a hypocontractile bladder.

\section{EPIDEMIOLOGY AND NATURAL HISTORY OF BPH}

The prevalence of male LUTS has increased over the last decade. In the first community-based study in Singapore in 1997, the prevalence of moderate-to-severe LUTS was $10 \%$, which at that time was threefold less than that of Scotland, the United States (US) and Japan. ${ }^{(5)}$ However, its prevalence increased to $14 \%$ and $16.5 \%$ in 2005 and 2012, respectively. ${ }^{(6,7)}$ As male LUTS is significantly related to age, the findings are consistent with Singapore's ageing population. An autopsy study showed that the histological prevalence of $\mathrm{BPH}$ was $8 \%, 50 \%$ and $80 \%$ in the fourth, sixth and ninth decades of life, respectively. ${ }^{(8)}$

Among the LUTS, urinary frequency, nocturia and weak stream are the three most common complaints. ${ }^{(5)}$ In a local study on nocturia, $52 \%$ of men woke up at least once a night to void. Those who voided three times or more each night had a significantly higher degree of bother, and sleep and rest disturbances. ${ }^{(9)}$ The degree of bother closely correlates with quality of life and health-seeking behaviour, although it correlates poorly with the severity of LUTS. ${ }^{(5)}$ In Singapore, less than $30 \%$ of patients with moderate-to-severe LUTS sought medical attention. ${ }^{(7)}$ The prevalence of bother among Singaporean men was ten times lower than that among men in Scotland, the US and Japan. ${ }^{(5)}$ The cause of this lower prevalence might be multifactorial, including lifestyle, climate, and the cultural and social expectations of patients. Thus, it is important to assess each patient's degree of bother when evaluating for LUTS, rather than only the symptoms score.

\section{PATHOPHYSIOLOGY OF BPH}

$\mathrm{BPH}$ is a nodular disease, rather than diffuse hyperplasia of the entire prostate gland..$^{(8)}$ Obstruction at the bladder outlet depends on not just the size but, more so, the site of the adenoma. ${ }^{(3)}$ Prostate adenoma causes distortion of the bladder neck and protrudes into the bladder lumen, which is seen as intravesical prostatic protrusion (IPP) on ultrasonography ${ }^{(10)}$ (Fig. 1).

IPP has much clinical relevance. Firstly, IPP is well correlated to prostatic obstruction, as verified in a pressure flow study. Patients with Grade 3 IPP were much more likely to have prostatic obstruction compared to those with Grade 1 IPP (94\% vs. 21\%). ${ }^{(11)}$ IPP is also a better predictor of obstruction compared to prostate volume and serum prostate-specific antigen (PSA). ${ }^{(12)}$ Secondly, the likelihood of successful voiding after acute urinary retention can be predicted by the grade of IPP. Patients with Grade 3 IPP were less likely to void compared to those with Grade 1 IPP $(67 \% \text { vs. } 36 \%)^{.13)}$ Thirdly, IPP can predict the progression of BPH. Patients with Grade 3 IPP were more likely to have clinical deterioration compared to those with Grade 1 IPP (44\% vs. 6\%) at a mean follow-up period of 32 months. ${ }^{(14)}$

Not all patients with Grade 3 IPP progress, so further management of $\mathrm{BPH}$ should be based on the severity of the

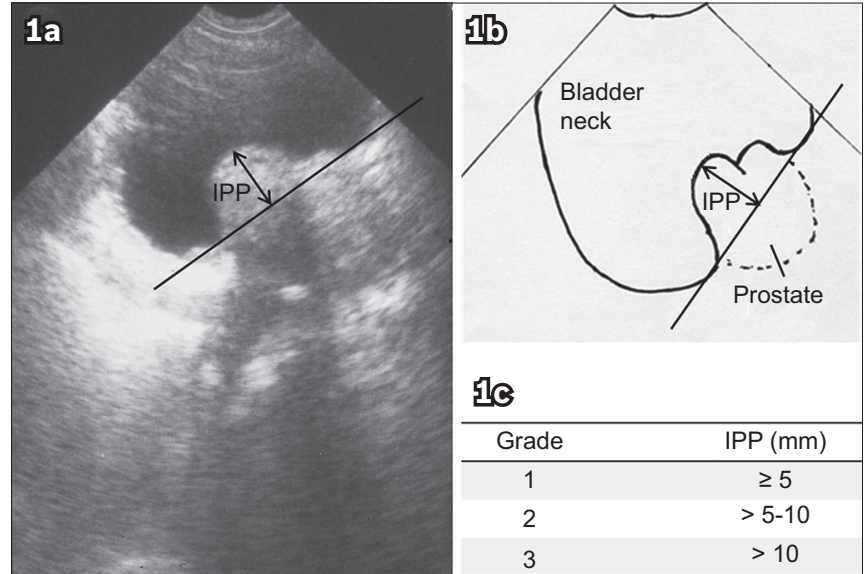

Fig. 1 (a) Transabdominal US image in mid-sagittal view of comfortably full bladder shows Grade 3 intravesical prostatic protrusion (IPP) with a measurement of $15 \mathrm{~mm}$. (b) Line drawing shows the same bladder with IPP measured from the protruding prostate tip perpendicularly down to the bladder circumference at the prostate base. (c) Table shows the IPP grading system.

Table I. Classification of severity of clinical benign prostatic hyperplasia (BPH) and suggested treatment by stage. ${ }^{(15,16)}$

\begin{tabular}{llll}
\hline Stage & $\begin{array}{l}\text { Significant } \\
\text { obstruction* }\end{array}$ & $\begin{array}{l}\text { Bothersome } \\
\text { symptoms }\end{array}$ & $\begin{array}{l}\text { Suggested } \\
\text { treatment }\end{array}$ \\
\hline I & Absent & Absent & $\begin{array}{l}\text { Watch and } \\
\text { counsel }\end{array}$ \\
II & Absent & Present & Medical treatment \\
III & Present & Irrespective & Surgical options \\
IV & $\begin{array}{l}\text { Complications } \\
\text { of clinical BPH }\end{array}$ & $\begin{array}{l}\text { Complications } \\
\text { of clinical BPH }\end{array}$ & Surgery \\
\hline
\end{tabular}

*Defined as persistent post-void residual urine volume $>100 \mathrm{~mL}$ or maximum voided volume $<100 \mathrm{~mL}$. +Quality of life score $\geq 3$.

disease, which can be classified according to the staging system (Table I). ${ }^{(15)}$ Disease severity is based on the presence or absence of significant prostatic obstruction (that impairs either the emptying or storage functions of the bladder) and the presence or absence of bothersome symptoms (quality of life [QOL] score $\geq 3$ ). ${ }^{(16)}$ Impaired emptying function should be suspected when there is persistently high (>100 mL) post-void residual urine volume (PVRU) on transabdominal ultrasonography. Impaired storage function should be suspected if the maximum voided volume is persistently low (generally $<100 \mathrm{~mL}$ ). Generally, there is good correlation between the stage of $\mathrm{BPH}$ and grade of IPP. However, when there is discordance between them, further investigations are necessary before definitive treatment. ${ }^{(17)}$

\section{INVESTIGATIONS FOR MALE LUTS/BPH} International Prostate Symptom Score and QOL score (Grade A for FPs and urologists)

The International Prostate Symptom Score (IPSS) is a validated patient-administered questionnaire that is useful to quantify the severity of LUTS. ${ }^{(18)}$ It categorises LUTS into mild (IPSS 0-7), moderate (IPSS 8-19) and severe (IPSS 20-35). However, its correlation with bladder outlet obstruction is not consistent. There are many clinical instances in which patients with low IPSS have significant obstruction and vice versa. While IPSS is highly recommended, it should not be used alone. The QOL 
score (0-6) is more important than IPSS in the assessment of symptoms, ${ }^{(5)}$ and is thus more useful in guiding treatment options.

\section{Focused physical examination (Grade A for FPs and urologists)}

If the kidney is ballotable or the bladder is palpable or percussable after a second void, specialist referral should be initiated.

\section{Digital rectal examination (Grade A for FPs and urologists)}

A hard, nodular prostate suggests possible malignancy. The size of the prostate may be estimated. A normal prostate is about two fingerbreadths. Digital rectal examination (DRE) may underestimate the size of a very large prostate. Poor anal tone and sacral anaesthesia suggest possible neurogenic voiding dysfunction.

\section{Transabdominal ultrasonography (Grade B for FPs, Grade A for urologists)}

While it may not be available in every FP's clinic, transabdominal ultrasonography is of value in the evaluation of male LUTS/BPH. These include (a) measurement of IPP and prostate volume: IPP is essential in diagnosing prostatic adenoma, with $100 \%$ specificity and $100 \%$ positive predictive value; ${ }^{(3)}(\mathrm{b})$ measurement of PVRU: PVRU > $100 \mathrm{~mL}$ should be considered significant only if it is persistent after a second void; (c) detection of bladder or renal stones; and (d) detection of hydronephrosis, which is more sensitive than serum creatinine level in detecting back pressure effects from bladder outlet obstruction.

\section{Urinalysis (Grade A for FPs and urologists)}

This helps to identify other causes of LUTS, such as diabetes mellitus and urinary tract infection. It may also detect proteinuria and microhaematuria for further evaluation.

Prostate-specific antigen (Grade A for FPs and urologists) Population screening for prostate cancer with PSA is controversial and not recommended. However, for patients who present with LUTS, PSA testing helps to detect prostate cancer and prostatitis. This is especially important when the DRE reveals an abnormal prostate. PSA testing should be done after a shared discussion with the patient on its pro and cons. It is particularly useful for men above 50 years of age with a life expectancy of more than ten years. A PSA value $>4 \mu \mathrm{g} / \mathrm{L}$ would need further evaluation. It is also proposed that PSA may be a good surrogate for estimating prostate volume. For prostate volume $>30 \mathrm{~g}$, PSA would be $>1.5 \mu \mathrm{g} / \mathrm{L} \cdot{ }^{(19)}$

\section{Voiding diary (Grade A for FPs and urologists)}

A voiding diary is a three-day frequency volume chart that documents the date/time of fluid intake and urine voided. The types of fluid and timing of sleep are also recorded. It is recommended for patients with mainly storage symptoms. Nocturnal polyuria (> 33\% of daily urine output at night), 24-hour polyuria or overactive bladder can be diagnosed using this method.

\section{Uroflowmetry (Grade A for urologists)}

Uroflowmetry is commonly performed in the urologist's clinic, together with ultrasonography measurement of PVRU, to monitor progression of $\mathrm{BPH}$. It is valid if the voided volume is $>150 \mathrm{~mL}$. Maximum flow rate (Qmax), the main parameter measured in uroflowmetry, correlates with bladder outlet obstruction. However, a lower Qmax does not confirm obstruction, while a high Qmax does not exclude obstruction. A Qmax $<10 \mathrm{~mL} / \mathrm{s}$ in properly performed uroflowmetry has about $90 \%$ accuracy in diagnosing obstruction. ${ }^{(18)}$ Grade 1 IPP with a Qmax $>20 \mathrm{~mL} / \mathrm{s}$ on uroflowmetry can exclude BPH as the cause of LUTS. ${ }^{(10)}$

\section{Flexible cystoscopy (Grade C for urologists)}

Flexible cystoscopy is not essential in the assessment of patients with LUTS/BPH. Its role in the setting of slow flow is to exclude urethral stricture in patients with a history of previous instrumentation, or with detrusor failure. It is also recommended for patients with gross haematuria, to exclude bladder cancer.

\section{Urodynamic studies (Grade $\mathbf{C}$ for urologists)}

Urodynamic studies are not useful for all male patients with LUTS. It is indicated for patients with storage symptoms and low-grade IPP suggestive of an overactive bladder. Additionally, it may be useful for patients with poor Qmax and low-grade IPP suggestive of a hypocontractile bladder.

\section{TREATMENTS FOR BPH}

In a local study, $59 \%$ of patients were managed conservatively, $32 \%$ were prescribed medications and $9 \%$ underwent surgery. ${ }^{(14)}$ This corresponded to the natural history of $\mathrm{BPH} .{ }^{(20)}$

\section{Watchful waiting (Grade A)}

Watchful waiting is suitable for patients with low-stage $\mathrm{BPH}$. Those with no bothersome symptoms and no high PVRU are ideal. They can be reassured that their symptoms are unlikely to result in bladder or kidney dysfunction, as most patients are concerned about the long-term effects of $\mathrm{BPH}$, rather than their immediate symptoms. ${ }^{(21)}$ Lifestyle adjustments, such as regular exercise and restriction of caffeine, alcohol and evening fluid intake, may improve storage symptoms such as urgency and nocturia.

\section{Medications}

The mechanism of action, efficacy, side effects and clinical considerations of the medications for $\mathrm{BPH}$ are discussed.

\section{Alpha-1 antagonists}

- Mechanism of action: They block the alpha-1 receptors in the prostatic urethra and around the bladder neck. This results in a decrease in smooth muscle tone, thus reducing the dynamic component of prostatic obstruction. ${ }^{(22)}$

- Efficacy: They improve IPSS by $30 \%-40 \%$ and the flow 
rate by $20 \%-25 \% .{ }^{(23)}$ However, they do not prevent the progression of $\mathrm{BPH} .{ }^{(24,25)}$ Patients usually experience the full therapeutic effect of alpha-1 antagonists within one week. ${ }^{(26)}$

- $\quad$ Side effects: These include postural dizziness and hypotension, which may lead to falls among elderly patients. Patients may also experience other side effects from vasodilatation such as nasal congestion, and side effects from bladder neck relaxation such as abnormal ejaculation. ${ }^{(27)}$

- Clinical considerations: Alpha-1 antagonists should be prescribed with caution because of their side effects and provide only symptomatic relief without prevention of disease progression. Therefore, prescriptions should be regularly reviewed and adjusted based on the latest symptoms (Grade A). When dosed correctly, the efficacy of various alpha- 1 antagonists is similar. ${ }^{(23)}$ Factors such as the patient's social and financial background should be considered when deciding which alpha-1 antagonist to prescribe.

\section{5-alpha reductase inhibitors}

- Mechanism of action: They block the enzymatic conversion of testosterone to dihydrotestosterone, resulting in prostatic epithelial atrophy. ${ }^{(28)}$ This results in a decrease in prostatic volume, thus reducing the static component of prostatic obstruction.

- $\quad$ Efficacy: Patients often experience full therapeutic effects after six months of treatment. ${ }^{(24,25)}$ The efficacy is more pronounced in those with larger prostatic volumes. For prostatic volumes $<30 \mathrm{~g}$, efficacy is minimal. ${ }^{(24,29)}$ They have been shown to prevent $\mathrm{BPH}$ progression and decrease the incidence of acute urinary retention and $\mathrm{BPH}$-related surgery for up to four years. ${ }^{(24,25)}$

- $\quad$ Side effects: The decrease in dihydrotestosterone results in a drop in androgenic stimulation, leading to sexual dysfunctions such as decreased libido and erectile dysfunction. In view of the hormonal nature of their mechanism of action, 5-alpha reductase inhibitors were once evaluated for prostate cancer prevention. It was found that they reduced the overall incidence of prostate cancer, but the relative risk of high-grade malignancy was increased. ${ }^{(30,31)}$

- $\quad$ Clinical considerations: They are indicated for patients with prostate volumes $>30 \mathrm{~g}$ and significant obstruction (Stage III BPH; Grade A). There should be increased vigilance for prostate cancer when using 5-alpha reductase inhibitors, since their association with high-grade malignancy has not been clearly ruled out (Grade A).

\section{Combination therapy with alpha-1 antagonist and 5-alpha reductase inhibitors}

Such a combination has the benefits of rapid onset of symptomatic relief by an alpha- 1 antagonist and prevention of $\mathrm{BPH}$ progression by a 5 -alpha reductase inhibitor. However, side effects may also be more significant than monotherapy with either medication. ${ }^{(24,25)}$
Combination therapy can be considered among patients with prostate volumes $>30 \mathrm{~g}$ and who do not respond well to alpha-1 antagonist monotherapy (Grade B).

\section{Anti-muscarinic agents}

- Mechanism of action: They inhibit the response of acetylcholine receptors to parasympathetic stimulus. Blockage of such receptors in the bladder results in a decrease in the contractility of the detrusor muscles and a decrease in the number of abnormal detrusor contractions, thus reducing the storage symptoms of urinary frequency and urgency. ${ }^{(32)}$

- $\quad$ Efficacy: Anti-muscarinic agents significantly reduce urinary frequency, urgency and urge incontinence among men without significant prostatic obstruction. ${ }^{(33)}$

- $\quad$ Side effects: Dry mouth, dry eyes and constipation are the more commonly described side effects of anti-muscarinic agents. Most anti-muscarinic agents cross the blood-brain barrier, so they may lead to changes in mental status, especially among elderly patients. They increase PVRU, but may not increase the risk of acute urinary retention over a short period of use $\left(<12\right.$ weeks). ${ }^{(34)}$ There is no study to support the prolonged use of anti-muscarinic agents among men with bladder outlet obstruction.

- $\quad$ Clinical considerations: Patients with storage symptoms and no significant bladder outlet obstruction may be treated with anti-muscarinic agents alone (Grade B). Combination therapy with an anti-muscarinic agent and alpha-1 antagonist may be prescribed for patients with reduced maximum urine flow rate and low-grade IPP. ${ }^{(35)}$ Such a combination should be avoided among patients with bladder outlet obstruction, identifiable by high-grade IPP, reduced maximum urine flow rate and high PVRU (Grade B).

\section{Phosphodiesterase-5 inhibitors}

- Mechanism of action: The exact mechanism of phosphodiesterase- 5 inhibitors on the management of male LUTS/BPH has not been completely elucidated. Some of the possible mechanisms include relaxation of smooth muscle tones in the lower urinary tract caused by increased cyclic guanosine monophosphate, inhibition of local inflammatory processes, and improvement in blood flow and oxygenation to the lower urinary tract. ${ }^{(36-38)}$

- $\quad$ Efficacy: Most studies demonstrate improvements in IPSS and QOL, but no significant improvement in Qmax. ${ }^{(39)}$ Only tadalafil $5 \mathrm{mg}$ daily has been approved for use in male LUTS by the US Food and Drug Administration and Health Sciences Authority, Singapore.

- $\quad$ Side effects: Nasal congestions, facial flushing, headache and dyspepsia have been described. It is contraindicated among patients who are already taking nitrates or alpha antagonists, due to the risk of significant hypotension.

- Clinical considerations: tadalafil $5 \mathrm{mg}$ daily may be considered for men with erectile dysfunction and bothersome LUTS (Stage II BPH; Grade C). 


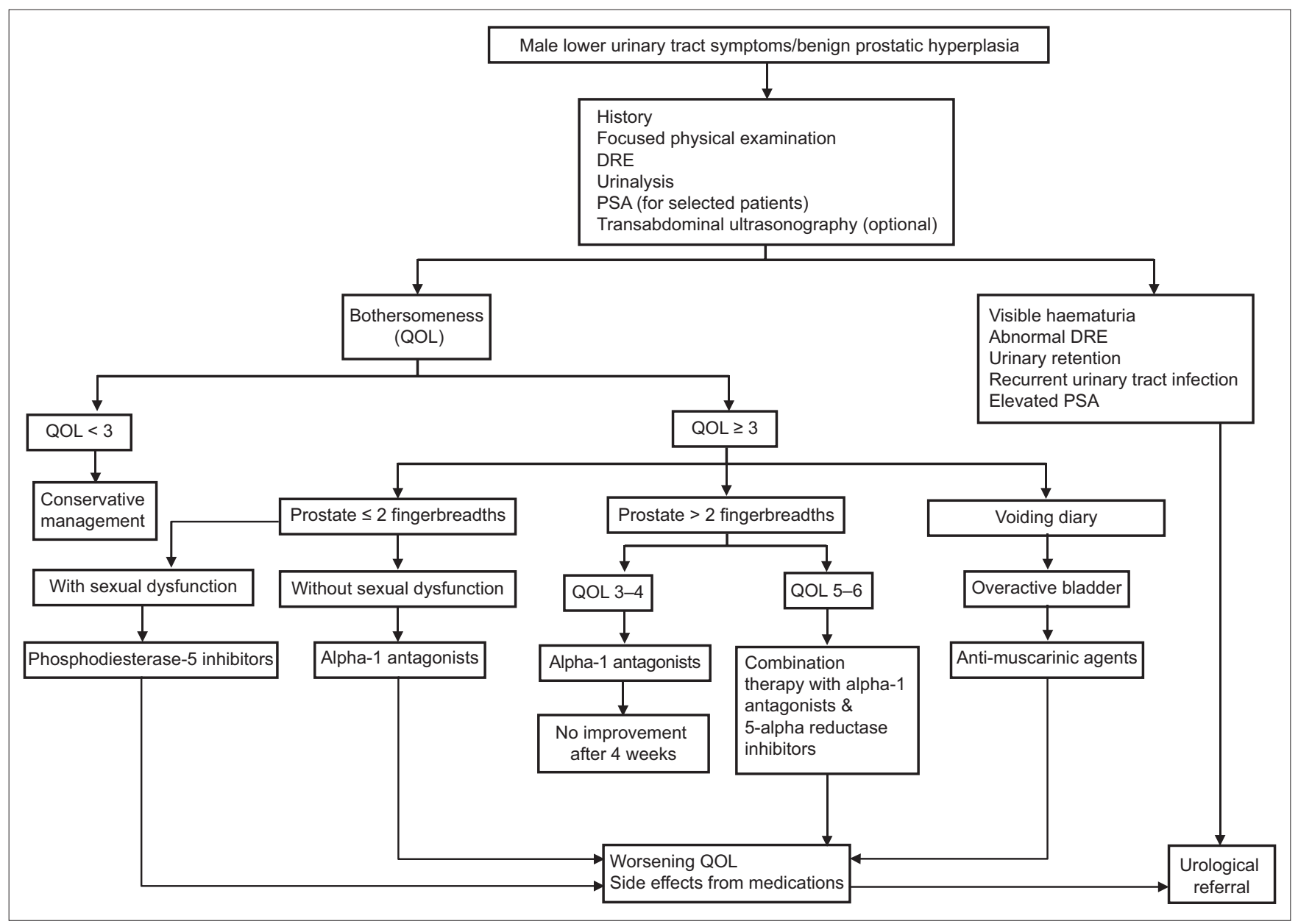

Fig. 2 Care flow for family practitioners. DRE: digital rectal examination; PSA: prostate-specific antigen; QOL: quality of life

\section{Phytotherapy (Grade C)}

Available studies have provided conflicting reports on the efficacy of phytotherapy agents. ${ }^{(40)}$ The anti-inflammatory property of phytotherapeutic agents may suggest its use among patients with bothersome symptoms and small prostates who are unsuitable for 5 -alpha reductase inhibitors. ${ }^{(41)}$

\section{Surgical options}

Indications for surgery include Stage IV BPH and failed medical therapy seen in persistent bothersome symptoms or side effects of medications. A myriad of technology is available worldwide, but only those with local relevance have been updated. While transurethral resection of the prostate (TURP) remains the gold standard in urological care, there are recent improvements.

\section{Bipolar TURP (Grade A)}

Bipolar technology permits resection with normal saline instead of glycine, negating the potentially serious complication of transurethral resection syndrome. ${ }^{(42)}$ This permits a longer resection time in larger prostates, leading to safer outcomes.

\section{Enucleation of obstructing prostatic adenoma (Grade A)} About $7.4 \%$ of TURP patients require repeat resection by eight years after surgery due to recurrent prostatic adenoma. ${ }^{(43)}$ Enucleation, instead of resection, may help to reduce the incidence of recurrence, as it removes obstructing adenomas more completely, resulting in better long-term outcomes. ${ }^{(4)}$ Transurethral enucleation can be performed with laser or diathermy devices. Enucleation of prostate adenoma may also be performed with open or minimally invasive surgery. These are useful approaches in cases of concomitant bladder diverticulectomy, or when there is a large bladder stone.

\section{Transurethral laser prostatectomy (Grade B)}

Transurethral laser prostatectomy has various techniques, ranging from vaporisation to enucleation. The main advantage of the procedure is better haemostasis, which permits its use even while patients are on antiplatelet drugs. The high cost of transurethral laser prostatectomy has limited the widespread adoption of this technique.

\section{Minimally invasive procedures (Grade C)}

In transurethral needle ablation of the prostate, radiofrequency needles are inserted into the prostate. Studies have shown an IPSS reduction from 21 to 7, and an improvement in Qmax from $10 \mathrm{~mL} / \mathrm{s}$ to $15 \mathrm{~mL} / \mathrm{s}$. Its results are limited by the inability to treat the bladder neck and median prostate lobe. At two years, $14 \%$ of patients need further interventions. ${ }^{(45)}$ Transurethral needle ablation 


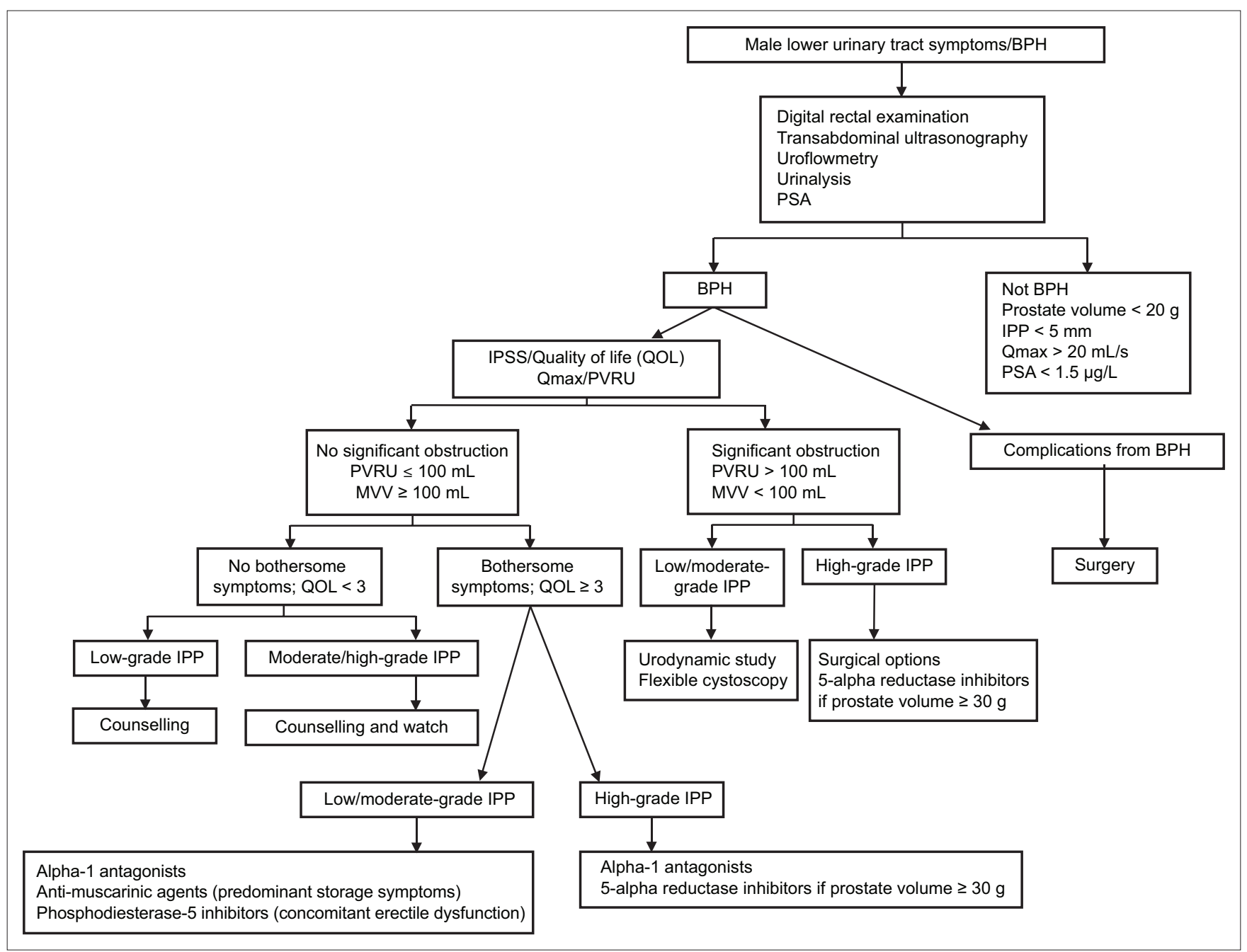

Fig. 3 Care flow for urologists. BPH: benign prostatic hyperplasia; IPP: intravesical prostatic protrusion; IPSS: International Prostate Symptom Score; MVV: maximum voided volume; PSA: prostate-specific antigen; PVRU: post-void residual urine volume; Qmax: maximum flow rate

may be considered for patients who do not have a satisfactory response to medications but cannot accept the possibility of retrograde ejaculation and sexual dysfunctions after TURP.

\section{UROLOGICAL REFERRAL}

FPs should initiate specialist referral when their clinical evaluations reveal a history of visible haematuria, an abnormal prostate examination or a persistently palpable bladder. Other indications include the presence of urinary tract infection, elevated serum PSA level or poor response to medical therapy for LUTS.

\section{CONCLUSION}

These updated recommendations help FPs and urologists to differentiate BPH from other causes of male LUTS. By doing so, care and management can be individualised for each patient. Treatment should be decided according to the severity of the disease, taking into consideration the patient's expectations, and social and financial background. We propose care flows for male LUTS/BPH that focus on the skills and tools available to FPs and urologists (Figs. 2 \& 3). This would achieve the goal of seamless and cost-effective management of this common condition.

\section{ACKNOWLEDGEMENTS}

We would like to thank Dr Toh Khai Lee and Dr Tan Yeh Hong, past presidents of the Singapore Urological Association, for their advice and support, as well as Dr Reshma Kaur Mangat, Dr Huang Hong Hong and Ms Ng Mei Ying for their editorial and secretarial assistance.

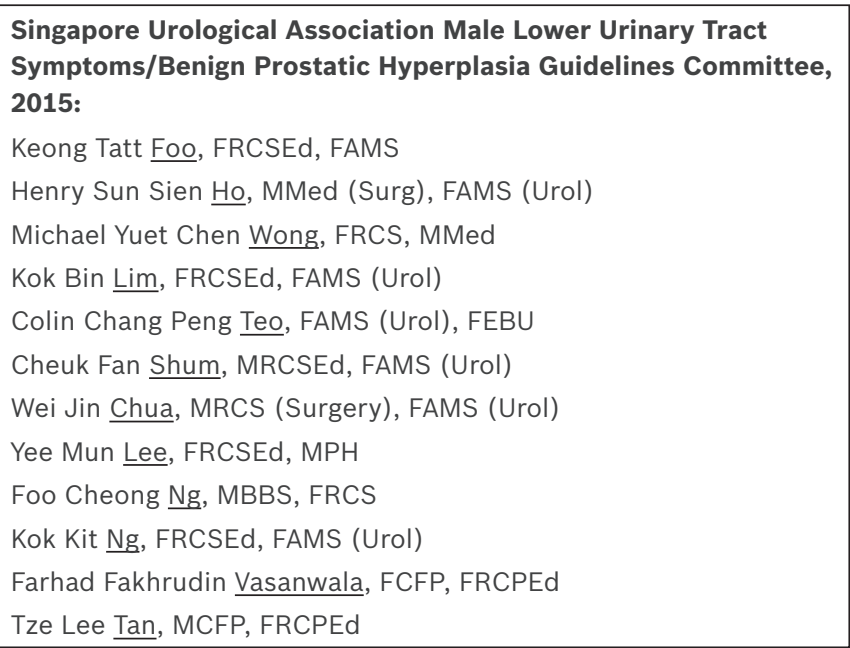




\section{REFERENCES}

1. Ministry of Health Singapore. Clinical Practice Guidelines: Lower Urinary Tract Symptoms Suggestive of Benign Prostatic Hyperplasia. Jan 2005 [online]. Available at: https://www.moh.gov.sg/content/dam/moh_web/HPP/Doctors/ cpg_medical/withdrawn/cpg_Lower\%20Urinary\%20Tract $\% 20$ Symptoms $\% 20$ Suggestive $\% 20$ of $\% 20$ Benign $\% 20$ Prostatic\%20Hyperplasia-Jan\%202005.pdf. Accessed November 22, 2016.

2. Abrams P, Cardozo L, Fall M, et al; Standardisation Sub-committee of the International Continence Society. The standardisation of terminology of lowe urinary tract function: report from the Standardisation Sub-committee of the International Continence Society. Neurourol Urodyn 2002; 21:167-78.

3. Luo GC, Foo KT, Kuo T, Tan G. Diagnosis of prostate adenoma and the relationship between the site of prostate adenoma and bladder outlet obstruction. Singapore Med I 2013; 54:482-6.

4. McNeal JE. Normal histology of the prostate. Am J Surg Pathol 1988; 12:619-33.

5. Tan HY, Choo WC, Archibald C, Esuvaranathan K. A community based study of prostatic symptoms in Singapore. J Urol 1997; 157:890-3.

6. Li MK, Garcia LA, Rosen R. Lower urinary tract symptoms and male sexua dysfunction in Asia: a survey of ageing men from five Asian countries. BJU Int 2005; 96:1339-54.

7. Chong C, Fong L, Lai R, et al. The prevalence of lower urinary tract symptoms and treatment-seeking behaviour in males over 40 years in Singapore: a community-based study. Prostate Cancer Prostatic Dis 2012; 15:273-7.

8. Berry SJ, Coffey DS, Walsh PC, Ewing LL. The development of human benign prostatic hyperplasia with age. J Urol 1984; 132:474-9.

9. Liew LC, Tiong HY, Wong ML, Png DC, Tan JK. A population study of nocturia in Singapore. BJU Int 2006; 97:109-12.

10. Yuen JS, Ngiap JT, Cheng CW, Foo KT. Effects of bladder volume on transabdominal ultrasound measurements of intravesical prostatic protrusion and volume. Int J Urol 2002; 9:225-9.

11. Chia SJ, Heng CT, Chan SP, Foo KT. Correlation of intravesical prostatic protrusion with bladder outlet obstruction. BJU Int 2003; 91:371-4.

12. Lim KB, Ho H, Foo KT, Wong MY, Fook-Chong S. Comparison of intravesical prostatic protrusion, prostate volume and serum prostatic-specific antigen in the evaluation of bladder outlet obstruction. Int J Urol 2006; 13:1509-13.

13. Tan $\mathrm{YH}$, Foo KT. Intravesical prostatic protrusion predicts the outcome of a trial without catheter following acute urine retention. J Urol 2003; 170(6 Pt 1):2339-41.

14. Lee LS, Sim HG, Lim KB, Wang D, Foo KT. Intravesical prostatic protrusion predicts clinical progression of benign prostatic enlargement in patients receiving medical treatment. Int J Urol 2010; 17:69-74.

15. Foo KT. Current assessment and proposed staging of patients with benign prostatic hyperplasia. Ann Acad Med Singapore 1995; 24:648-51.

16. Wang D, Foo KT. Staging of benign prostate hyperplasia is helpful in patients with lower urinary tract symptoms suggestive of benign prostate hyperplasia. Ann Acad Med Singapore 2010; 39:798-802.

17. Wang D, Huang H, Law YM, Foo KT. Relationships between prostatic volume and intravesical prostatic protrusion on transabdominal ultrasound and benign prostatic obstruction in patients with lower urinary tract symptoms. Ann Acad Med Singapore 2015; 44:60-5.

18. de la Rosette J, Perachino M, Thomas D, et al. Guidelines on benign prostatic hyperplasia. European Association of Urology [online]. Available at: https://uroweb.org/wp-content/uploads/EAU-Guidelines-Bening-ProstaticHyperplasia-2001.pdf. Accessed November 22, 2016.

19. Roehrborn CG. The utility of serum prostatic-specific antigen in the management of men with benign prostatic hyperplasia. Int J Impot Res 2008; 20 Suppl 3:S19-26.

20. Ball AJ, Feneley RC, Abrams PH. The natural history of untreated "prostatism". Br J Urol 1981; 53:613-6.

21. Emberton M. Medical treatment of benign prostatic hyperplasia: physician and patient preferences and satisfaction. Int J Clin Pract 2010; 64:1425-35.

22. Michel MC, Vrydag W. Alpha1-, alpha2- and beta-adrenoceptors in the urinary bladder, urethra and prostate. Br J Pharmacol 2006; 147 Suppl 2:S88-119.

23. Djavan B, Chapple C, Milani S, Marberger M. State of the art on the efficacy and tolerability of alpha1-adrenoceptor antagonists in patients with lowe urinary tract symptoms suggestive of benign prostatic hyperplasia. Urology $2004 ; 64: 1081-8$.
24. Roehrborn CG, Siami P, Barkin J, et al; CombAT Study Group. The effects of combination therapy with dutasteride and tamsulosin on clinical outcomes in men with symptomatic benign prostatic hyperplasia: 4-year results from the CombAT study. Eur Urol 2010; 57:123-31.

25. McConnell JD, Roehrborn CG, Bautista OM, et al; Medical Therapy of Prostatic Symptoms (MTOPS) Research Group. The long-term effect of doxazosin, finasteride, and combination therapy on the clinical progression of benign prostatic hyperplasia. N Engl J Med 2003; 349:2387-98.

26. Milani S, Djavan B. Lower urinary tract symptoms suggestive of benign prostatic hyperplasia: latest update on alpha-adrenoceptor antagonists. BJU Int 2005; 95 Suppl 4:29-36.

27. Lepor $\mathrm{H}$. Alpha blockers for the treatment of benign prostatic hyperplasia. Rev Urol 2007; 9:181-90.

28. Rittmaster RS, Norman RW, Thomas LN, Rowden G. Evidence for atrophy and apoptosis in the prostates of men given finasteride. J Clin Endocrinol Metab 1996; 81:814-9.

29. Boyle P, Gould AL, Roehrborn CG. Prostate volume predicts outcome of treatment of benign prostatic hyperplasia with finasteride: meta-analysis of randomized clinical trials. Urology 1996; 48:398-405.

30. Thompson IM, Goodman PJ, Tangen CM, et al. The influence of finasteride on the development of prostate cancer. N Engl J Med 2003; 349:215-24.

31. Andriole GL, Bostwick DG, Brawley OW, et al; REDUCE Study Group. Effect of dutasteride on the risk of prostate cancer. N Engl J Med 2010; 362:1192-202.

32. Andersson KE, Yoshida M. Antimuscarinics and the overactive detrusor--which is the main mechanism of action? Eur Urol 2003; 43:1-5.

33. Höfner K, Burkart M, Jacob G, Jonas U. Safety and efficacy of tolterodine extended release in men with overactive bladder symptoms and presumed non-obstructive benign prostatic hyperplasia. World J Urol 2007; 25:627-33.

34. Abrams P, Kaplan S, De Koning Gans HJ, Millard R. Safety and tolerability of tolterodine for the treatment of overactive bladder in men with bladder outlet obstruction. J Urol 2006; 175(3 Pt 1):999-1004.

35. Kaplan SA, Roehrborn CG, Rovner ES, et al. Tolterodine and tamsulosin for treatment of men with lower urinary tract symptoms and overactive bladder: a randomized controlled trial. JAMA 2006; 296:2319-28.

36. Giuliano F, Ückert S, Maggi M, et al. The mechanism of action of phosphodiesterase type 5 inhibitors in the treatment of lower urinary tract symptoms related to benign prostatic hyperplasia. Eur Urol 2013; 63:506-16.

37. Vignozzi L, Gacci M, Cellai I, et al. PDE5 inhibitors blunt inflammation in human BPH: a potential mechanism of action for PDE5 inhibitors in LUTS. Prostate 2013; 73:1391-402

38. Morelli A, Sarchielli E, Comeglio P, et al. Phosphodiesterase type 5 expression in human and rat lower urinary tract tissues and the effect of tadalafil on prostate gland oxygenation in spontaneously hypertensive rats. J Sex Med 2011; 8:2746-60

39. Brock GB, McVary KT, Roehrborn CG, et al. Direct effects of tadalafil on lower urinary tract symptoms versus indirect effects mediated through erectile dysfunction symptom improvement: integrated data analyses from 4 placebo controlled clinical studies. J Urol 2014; 191:405-11.

40. Tacklind J, MacDonald R, Rutks I, Stanke JU, Wilt TJ. Serenoa repens for benign prostatic hyperplasia. Cochrane Database Syst Rev 2012; 12:CD001423.

41. Wilt T, Ishani A, Mac Donald R, Rutks I, Stark G. Pygeum africanum for benign prostatic hyperplasia. Cochrane Database Syst Rev 2002; 1:CD001044.

42. Ho HS, Yip SK, Lim KB, et al. A prospective randomized study comparing monopolar and bipolar transurethral resection of prostate using transurethral resection in saline (TURIS) system. Eur Urol 2007; 52:517-22.

43. Madersbacher S, Lackner J, Brössner C, et al; Prostate Study Group of the Austrian Society of Urology. Reoperation, myocardial infarction and mortality after transurethral and open prostatectomy: a nation-wide, long-term analysis of 23,123 cases. Eur Urol 2005; 47:499-504.

44. Luo YH, Shen JH, Guan RY, Li H, Wang J. Plasmakinetic enucleation of the prostate vs plasmakinetic resection of the prostate for benign prostatic hyperplasia: comparison of outcomes according to prostate size in 310 patients. Urology 2014; 84:904-10.

45. Hill B, Belville W, Bruskewitz R, et al. Transurethral needle ablation versus transurethral resection of the prostate for the treatment of symptomatic benign prostatic hyperplasia: 5-year results of a prospective, randomized, multicenter clinical trial. J Urol 2004; 171(6 Pt 1):2336-40. 


\section{SINGAPORE MEDICAL COUNCIL CATEGORY 3B CME PROGRAMME} (Code SMJ 201708C)

Question 1. Regarding clinical benign prostatic hyperplasia (BPH):

(a) Both large and small prostates can cause bladder outlet obstruction.

(b) Its location at the lateral lobes of the prostate causes more severe obstruction than at the middle lobe.

(c) Clinical BPH can cause severe obstruction without symptoms.

(d) Clinical $\mathrm{BPH}$ is defined as prostatic adenoma/adenomata causing varying degrees of bladder outlet obstruction, irrespective of symptoms.

Question 2. Regarding the role of digital rectal examination (DRE) in evaluating male lower urinary tract symptoms (LUTS)/BPH:

(a) The shape of the prostate can be accurately determined using DRE.

(b) The size of a normal prostate is two fingerbreadths or less.

(c) A hard nodular prostate suggests prostatitis.

(d) Poor anal tone and sacral anaesthesia suggest possible neurogenic voiding dysfunction.

Question 3. Regarding the use of a voiding diary for investigating male LUTS:

(a) It is a 48-hour frequency volume chart that documents the date/time of fluid intake and urine voided.

(b) The timing of dinner and lunch must be recorded.

(c) It is recommended for patients with mainly storage symptoms.

(d) Nocturia polyuria is defined as $>33 \%$ of the daily urine output at night.

Question 4. Regarding medical therapy for BPH:

(a) Alpha-1 antagonists are effective in preventing $\mathrm{BPH}$ progression, with significant reduction in the risks of BPH-related acute urinary retention and surgery.

(b) Since 5-alpha reductase inhibitors decrease prostatic volume, these drugs should be routinely used as first-line treatment in $\mathrm{BPH}$ patients.

(c) With the lower urinary tract being the primary target of action, the ability to cross the blood-brain barrier is not a clinical concern when using anti-muscarinic agents.

(d) Medical therapy for BPH should have an individualised approach, taking into consideration both the clinical context and socioeconomic background of each BPH patient.

Question 5. Regarding surgical therapy for benign prostate obstruction:

(a) Acute retention of urine is an indication to offer surgery.

(b) Surgery can be offered to patients who have persistent bothersome symptoms in spite of medical therapy.

(c) Bipolar transurethral resection of the prostate has not reduced the incidence of transurethral surgery syndrome.

(d) Transurethral enucleation procedures remove obstructing adenoma/adenomata more completely and therefore give better long-term results.

\section{Doctor's particulars:}

Name in full:

MCR no.:

Specialty:

Email:

\footnotetext{
SUBMISSION INSTRUCTIONS:

Visit the SMJ website: http://www.smj.org.sg/current-issue and select the appropriate quiz. You will be redirected to the SMA login page.

For SMA member: (1) Log in with your username and password (if you do not know your password, please click on 'Forgot your password?'). (2) Select your answers for each quiz and click 'Submit'.

For non-SMA member: (1) Create an SMJ CME account, or log in with your SMJ CME username and password (for returning users). (2) Make payment of SGD 21.40 (inclusive of $7 \%$ GST) via PayPal to access this month's quizzes. (3) Select your answers for each quiz and click 'Submit'.

RESULTS:

(1) Answers will be published online in the SMJ October 2017 issue. (2) The MCR numbers of successful candidates will be posted online at the SMJ website by 9 October 2017. (3) Passing mark is $60 \%$. No mark will be deducted for incorrect answers. (4) The SMJ editorial office will submit the list of successful candidates to the Singapore Medical Council. (5) One CME point is awarded for successful candidates.

Deadline for submission: (August 2017 SMJ 3B CME programme): 12 noon, 2 October 2017.
} 